\title{
PENGARUH PELAKSANAAN KANGAROO MOTHER CARE (KMC) SELAMA SATU JAM TERHADAP SUHU TUBUH BAYI BERAT BADAN LAHIR RENDAH (BBLR) DI RUANG PERINATOLOGI RSUD PANDAN ARANG BOYOLALI
}

\author{
Setiyawan $^{1}$, Wahyu Deda Prajani ${ }^{2}$, Wahyu Dwi Agussafutri ${ }^{3}$ \\ ${ }^{1}$ STIKES Kusuma Husada Surakarta Prodi Sarjana Keperawatan \\ ${ }^{2}$ RSUD Pandan Arang Boyolali \\ ${ }^{3}$ STIKES Kusuma Husada Surakarta Prodi D3 Kebidanan
}

\begin{abstract}
Background: Low birth weight has the highest contribution to neonatal mortality rate. One of its complications is body temperature instability, and to maintain it, the infants are exposed to the Kangaroo Mother Care (KMC) method. The objective of this research is to investigate the one-hour KMC implementation on the body temperature of low birth weight infants at the Perinatology Room of Pandan Arang Local General Hospital of Boyolali. Method: This research used the quasi experimental method. It was conducted from October to November 2016. Its samples consisted of 22 infants and were determined through the accidental sampling technique. Its data were analyzed by using the Wilcoxon signed ranks test. Result: The result of the research shows that the average body temperatures prior to and following the implementation of one-hour KMC in Days 1, 2, and 3 were 36.660C and 37.070C. There was an effect of the implementation of one-hour KMC on the body temperature of low birth weight infants as indicated by the p-value which was less than 0.05. Conclusion: Thus, the future research is expected to develop the research by adding the research variables that may influence the body temperature stability of low birth weight infants in addition to the one-hour KMC.
\end{abstract}

Keywords: Low birth weight infants, KMC, Body temperature

\section{PENDAHULUAN}

Gangguan distress pernafasan merupakan masalah utama pada pasien di ruang rawat intensif karena manifestasi klinis distress pernafasan menyebabkan hipoksemia. Kondisi ini memerlukan penanganan segera dengan manejemen hipoksemia yang tepat karena akan berlanjut pada kondisi hipoksia jaringan melalui tindakan manajemen jalan nafas yang cepat. Salah satu tindakan manajemen jalan nafas buatan diruang intensif adalah intubasi endotracheal tube (ETT) untuk menjamin dan mempertahankan patensi jalan nafas, fasilitasi ventilasi dengan tekanan positif pada paru sehingga diharapkan dapat menurunkan kejadian hipoksemia serta dapat mencegah terjadinya inhalasi dan aspirasi saluran cerna.

Prevalensi bayi dengan Berat Badan Lahir Rendah (BBLR) diperkirakan $15 \%$ dari seluruh kelahiran di dunia dengan batasan 33\%-38\% lebih sering terjadi di negara-negara berkembang atau sosial ekonomi rendah. Data menunjukkan $90 \%$ kejadian BBLR terjadi di negara berkembang dan angka kematiannya 35 kali lebih tinggi dibanding pada bayi dengan berat lahir 
lebih dari 2500 gram (Proverawati dan Ismawati, 2010).

Hasil Riset Kesehatan Dasar (Riskesdas) tahun 2013, prevalensi bayi BBLR di Indonesia diperkirakan mencapai 2.103 bayi dari 18.948 bayi $(11,1 \%)$ yang ditimbang dalam kurun waktu 6-48 jam setelah melahirkan. Berdasarkan profil kesehatan provinsi Jawa Tengah jumlah bayi BBLR di Jawa Tengah pada tahun 2013 sebanyak 16.303 $(2,81 \%)$ meningkat bila dibandingan tahun 2012 sebesar 11.865 (2.08,\%). Menurut profil kesehatan kabupaten Boyolali (2013), di kabupaten Boyolali ditemukan angka kejadian BBLR sebanyak $139(0,84 \%)$ kasus dari 17.296 bayi lahir hidup dan jumlah ini meningkat dibandingkan tahun 2007 yaitu 94 $(0,65 \%)$ kasus dari 16.981 bayi lahir hidup. Di ruang perinatologi RSU Pandan Arang Boyolali, data bayi BBLR tahun 2015 sebanyak 97 (18,51\%), kasus dari 524 bayi lahir hidup.

Bayi Berat Badan Lahir Rendah (BBLR) adalah bayi dengan berat badan lahir kurang dari 2500 gram tanpa memandang masa kehamilan (Proverawati dan Ismawati, 2010). Bayi berat badan lahir rendah secara umum belum mempunyai kematangan dalam sistem pertahanan tubuh untuk beradaptasi dengan lingkungan ekstrauterin, sehingga berisiko menimbulkan komplikasi terutama ketidak stabilan suhu. Ketidakstabilan suhu pada BBLR terjadi karena cadangan lemak di bawah kulit tipis, pusat pengatur panas di otak belum matang, rasio luas permukaan terhadap berat badan yang besar dan produksi panas berkurang akibat lemak coklat yang tidak memadai serta ketidakmampuan untuk menggigil (Surasmi, 2003). Adanya ketidak keseimbangan panas (hipertermi dan hipotermi), bayi baru lahir akan berusaha menstabilkan suhu tubuhnya terhadap faktor-faktor penyebab.

Joanna Bridge Institute (2001) dikutip Hartini (2011) mengemukakan bahwa data statistik suatu rumah sakit khusus bayi mengindikasikan bahwa lebih dari $30 \%$ kunjungan ke ruang gawat darurat sebagai manifestasi utama disebabkan oleh demam/ hipertermi. Jannah (2015) menyatakan Angka kejadian demam di Indonesia sekitar 80\%-90\% dari keseluruhan hipertermi yang dilaporkan. Hipertermi dapat disebabkan oleh suhu lingkungan yang berlebihan, infeksi, dehidrasi atau perubahan mekanisme pengaturan panas sentral yang berhubungan dengan trauma lahir pada otak, malformasi dan obatobatan (Kosim, 2008).

Selain hipertermi, bayi BBLR dapat mengalami hipotermi sangat cepat dan menormalkan suhunya dapat membutuhkan waktu yang lama. Lunze (2014) menyatakan bahwa pada sebuah study berbasis masyarakat yang dilakukan di Sarlahi, Nepal, angka kematian neonatal meningkat $80 \%$ untuk setiap 1 derajad Celcius penurunan suhu tubuh. Hipotermia dapat mengakibatkan komplikasi jangka pendek berupa asidosis, hipoglikemia, serta peningkatan risiko untuk distres pernapasan. Risiko komplikasi dan kematian meningkat secara signifikan jika lingkungan termal tidak optimal (Karyuni dan Meiliya, 2008). Di rumah sakit, perawatan BBLR dengan inkubator selain jumlahnya yang terbatas, perawatan dengan inkubator memerlukan biaya.

$$
\text { Anderson (1991) dikutip }
$$

Rahmayanti (2011), menyatakan cara lain untuk mempertahankan suhu tubuh 
normal pada bayi BBLR adalah metode Kangaroo Mother Care (KMC) yaitu bayi selalu didekap ibu atau orang lain dengan kontak langsung kulit bayi. Pernyataan Perinasia (2008) yang dikutip oleh Syamsu (2013), bahwa perawatan metode kanguru bermanfaat dalam menstabilkan suhu tubuh bayi, stabilitas denyut jantung dan pernafasan, penggunaan kalori berkurang, kenaikan berat badan bayi lebih baik, waktu tidur bayi lebih lama, hubungan lekat bayi- ibu lebih baik (bounding) dan akan mengurangi terjadinya infeksi pada bayi.

Rubin dikutip Bahiyatun (2009) menyatakan bahwa adaptasi psikologi ibu post partum dibagi menjadi 3 fase yaitu: fase taking in, fase taking hold, dan fase letting go. Hari pertama sampai hari ke sepuluh ibu bayi masih tergantung dengan keluarga, maka ibu bayi diberikan kesempatan untuk melakukan KMC pada bayinya dengan metode intermitten .

Nyqvist (2010) dikutip Arifah (2015) menyatakan bahwa KMC dapat dilakukan dengan 2 cara, yaitu secara terus-menerus dalam 24 jam atau yang disebut juga dengan secara kontinyu dan yang kedua secara intermitten atau dengan cara selang-seling, dimana waktu dan durasi KMC tergantung dari respon tingkah laku bayi dan fisiologis ibu dengan durasi minimal selama 1 jam.

BBLR di Rumah Sakit Pandan Arang Boyolali memerlukan perawatan khusus di ruang Perinatologi. Perinatologi di RS Pandan Arang Boyolali adalah salah satu ruang rawat inap khusus yang memberikan pelayanan kesehatan bagi bayi baru lahir (usia 0-28 hari) dengan risiko tinggi, selain itu bayi dengan usia diatas 28 hari juga bisa dirawat di ruang ini dengan catatan berat badannya kurang dari 2500 gram. Selama bayi dirawat di perinatologi, hanya ibu bayi yang diperbolehkan masuk sehingga peran ibu dalam perawatan bayi berat badan lahir rendah dengan menggunakan metode KMC sangat penting. KMC di RSUD Pandan Arang Boyolali dimulai sejak tahun 2015 tetapi belum terdokumentasikan. Pada bulan Januari 2016, pelaksanaan KMC mulai terdokumentasi, namun pelaksanaannya belum maksimal. KMC dilaksanakan di ruangan dimana bayi dirawat, belum ada ruangan khusus untuk ibu-ibu yang melakukan KMC.

Hasil studi pendahuluan yang telah dilakukan, data rekam medik RSUD Pandan Arang Boyolali pada bulan Mei sampai bulan Juli 2016 didapatkan data bayi BBLR di ruang Perinatologi sebanyak 69 bayi dengan rincian hipertermi sebanyak 9 bayi (13\%), hipotermi sebanyak 38 bayi $(55,1 \%)$ dan suhu normal sebanyak 22 bayi $(31,9 \%)$. Hasil observasi yang dilakukan peneliti dari data kelahiran bayi BBLR sebanyak 69 bayi, baru 19 bayi $(27,5 \%)$ yang dilakukan KMC. Sepuluh ibu bayi $(14,5 \%)$ melakukan perawatan bayi dengan metode KMC kurang dari satu jam dan sembilan ibu bayi (13\%) melakukan KMC pada bayinya sekitar satu jam.

Berdasarkan adaptasi psikologi ibu post partum dimana hari pertama hingga hari ke sepuluh ibu bayi masih tergantung dengan keluarga maka diambil durasi minimal KMC selama 1 jam, serta ketidak stabilan suhu tubuh pada bayi BBLR dimana angka normotermi lebih kecil dibanding hipotermi dan adanya hipertermi pada BBLR di Ruang Perinatologi RSUD Pandan Arang Boyolali, maka dapat dirumuskan masalah : "Apakah ada pengaruh 
satu jam (post test) sebesar $37,07^{\circ} \mathrm{C}$. Sehingga tiga hari berturut-turut, terdapat kenaikan suhu rata-rata sebesar $0,41{ }^{\circ} \mathrm{C}$. Penelitian ini menunjukkan hari pertama, kedua dan ketiga semua suhu badan BBLR mengalami peningkatan, baik terhadap bayi yang mengalami hipotermi maupun hipertermi.

\section{Analisa Bivariat}

Suhu tubuh BBLR pre test dan post test pelaksanaan KMC di Ruang Perinatologi RSUD Pandan Arang Boyolali

Uji normalitas data menggunakan uji Saphiro wilk. Diperoleh data suhu tubuh BBLR sebelum dan sesudah dilaksanakan Kangaroo Mother Care (KMC) selama satu jam pada hari pertama mempunyai $p$-value masingmasing $(0,001$ dan 0,010), hari kedua mempunyai nilai $(0,001$ dan 0,001$)$ hari ketiga mempunyai nilai signifikan masing-masing $(0,001$ dan 0,002$)$, karena $p$-value $<0,05$ sehingga data dikatakan tidak berdistribusi normal (Sugiyono,2011). Maka pengujian hipotesis yang digunakan dalam penelitian ini digunakan analisis dengan Wilcoxon signed ranks test. Uji pengaruh pelaksanaan KMC selama satu jam di Ruang Perinatologi RSUD Pandan Arang Boyolali ditampilkan dalam tabel 3.

Tabel 3. Suhu Tubuh BBLR Pre Test dan Post Test pelaksanaan KMC di ruang Perinatologi RSUD Pandan Arang Boyolali

\begin{tabular}{|c|c|c|c|}
\hline Keterangan & Mean & t-test & $p$ \\
\hline $\begin{array}{l}\text { Suhu tubuh } \\
\text { pre-post }(H 1-1)\end{array}$ & $\begin{array}{l}36,65 \\
36,98\end{array}$ & 4,131 & 0.001 \\
\hline $\begin{array}{l}\text { Suhu tubuh } \\
\text { pre-post }(H 2-2)\end{array}$ & $\begin{array}{l}36,72 \\
37,09\end{array}$ & 4,125 & 0.001 \\
\hline
\end{tabular}

Suhu tubuh 36,61 pre-post (H3-3) $\quad 37,02$ $4,123 \quad 0.001$

Suhu tubuh 36,65 pre-post (H1-2) $\quad 37,09$ $2,303 \quad 0.021$

Suhu tubuh 36,65 pre-post (H1-3) 37,02

$2,458 \quad 0.014$

Dari Tabel 3 diketahui perbedaan nilai rata-rata suhu tubuh BBLR pada pre test - post test $\mathrm{KMC}$ selama satu jam hari pertama, kedua dan ketiga dengan $p=$ 0,001 . Demikian juga untuk mengetahui perbedaan nilai rata-rata suhu tubuh pada pre test hari pertama dengan post test hari kedua diketahui nilai $p=0,021$, serta pre test hari pertama dengan post test hari ketiga nilai $p=0,014$, karena $p \leq 0,05$ hal ini menunjukkan Ha gagal tolak, sehingga diketahui bahwa terdapat pengaruh pelaksanaan Kangaroo Mother Care (KMC) selama satu jam terhadap suhu tubuh bayi BBLR di Ruang Perinatologi RSUD Pandan Arang Boyolali.

Mendiskriptifkan karakteristik masingmasing variabel yang diteliti berdasarkan jenis kelamin, umur, dan penyakit pasien, ukuran ETT dan tekanan cuff ETT yang ditampilkan dalam distribusi tabel berikut:

\section{PEMBAHASAN}

Analisa Univariat

Distribusi responden pada tabel 1, menunjukkan responden berjenis kelamin perempuan berjumlah 13 bayi $(59,1 \%)$ dan laki-laki berjumlah 9 bayi $(40,9 \%)$ dimana semuanya mengalami peningkatan suhu. Tamsuri (2007), menyatakan bahwa pada umumnya orang dengan jenis kelamin laki-laki dapat meningkatkan kecepatan metabolisme basal kira-kira 10\%-15\% kecepatan normal, sehingga menyebabkan peningkatan produksi panas, sedangkan 
pada wanita fluktuasi suhu lebih bervariasi dari pria. Pada penelitian sebelumnya yang diteliti oleh Permatasari (2012), mengemukakan bahwa responden dengan jenis kelamin laki-laki lebih banyak mengalami kenaikan suhu tubuh dibanding responden perempuan. Penelitian tersebut mempunyai asumsi bahwa jenis kelamin dimungkinkan dapat mempengaruhi suhu tubuh bayi BBLR.

Berat badan bayi antara 15002500 gram merupakan yang terbanyak yaitu 17 orang (77,3\%). Suhermi (2009) menyatakan bahwa perubahan kondisi suhu terjadi pada neonatus yang baru lahir, di dalam tubuh ibunya, begitu lahir maka hubungan dengan ibunya sudah terputus dan neonatus harus mempertahankan suhu tubuhnya sendiri melalui aktifitas metabolismenya. Semakin kecil tubuh neonatus, semakin tinggi rasio permukaan tubuh dengan massanya, dan semakin sedikit cadangan lemaknya, sehingga meningkatkan kehilangan panas. Semakin meningkat berat badan bayi, semakin meningkat pula metabolisme basalnya, dimana metabolisme basal berperan penting untuk mempertahankan suhu tubuh, jadi berat badan dapat mempengaruhi suhu tubuh bayi.

Hasil penelitian ini menunjukkan bahwa usia responden terbesar antara 0 28 hari, yaitu 21 orang $(95,5 \%)$. Tamsuri (2006) mengemukakan bahwa usia mempengaruhi metabolisme tubuh akibat mekanisme hormonal sehingga memberi efek tidak langsung terhadap suhu tubuh. Pada neonatus dan bayi terdapat mekanisme pembentukan panas melalui metabolisme lemak coklat sehingga terjadi proses thermogenesis taanpa menggigil (non-shiverring). Berdasarkan hasil penelitian yang dilakukan oleh
Jeffrey (2003) dikutip Hartini (2011) menyatakan bahwa bayi berumur kurang dari 2 bulan lebih sering menunjukkan demam sebagai respon terhadap infeksi yang bersifat self limited dan berlangsung tidak lebih dari 3 hari. Jadi penelitian tersebut mempunyai asumsi bahwa usia mempengaruhi perubahan suhu.

\section{Analisa Bivariat}

Penelitian ini terdapat pengaruh pelaksanaan Kangaroo Mother Care (KMC) selama satu jam terhadap suhu tubuh bayi BBLR di Ruang Perinatologi RSUD Pandan Arang Boyolali. Dimana hari pertama, kedua dan ketiga semua suhu badan BBLR mengalami peningkatan, baik terhadap bayi yang mengalami hipotermi maupun hipertermi.

Pada bayi BBLR terjadi hipotermi karena jaringan lemak subkutan rendah dan luas permukaan tubuh relatif besar dibandingkan bayi BBLC (Sudarti \& Fauziah, 2013). Arifah dan Kartinah (2008) menyatakan bahwa neonatus full term mempunyai kemampuan menggigil dengan terbatas untuk menghasilkan panas, sedangkan bayi preterm tidak sama sekali. Bayi BBLR mempunyai respon vasomotor tidak stabil sehingga tidak dapat berkonstriksi secara adekuat untuk memperlambat kehilangan panas, serta mempunyai simpanan lemak coklat terbatas, sehingga tidak dapat menghasilkan panas dengan adekuat. Jaringan lemak coklat termasuk dalam homeoterm nonshivering thermogenesis, dimana metabolisme panas dihasilkan tanpa tanpa adanya kontraksi cepat otototot. Jaringan lemak coklat terutama terdistribusi pada bayi baru lahir untuk menghasilkan produksi panas yang paling efisien untuk kebutuhan bayi. Metabolisme produksi panas ini pada 
neonatus dimulai pada saat lahir dan puncaknya sekitar satu jam setelah itu. Jaringan lemak coklat mengelilingi organ vital berfungsi untuk menghasilkan kebutuhan panas, yang bekerja secara optimal dan mengelilingi arteri yang berfungsi untuk kehangatan darah sebelum disirkulasi melalui tubuh. Jadi untuk menghasilkan metabolisme panas pada neonatus diperlukan waktu sekitar satu jam.

KMC merupakan alternatif pengganti incubator dalam perawatan BBLR, dengan beberapa kelebihan antara lain: merupakan cara yang efektif untuk memenuhi kebutuhan bayi yang paling mendasar yaitu adanya kontak kulit bayi ke kulit ibu, dimana tubuh ibu akan menjadi thermoregulator bagi bayinya (Endyarni, 2013). KMC pada penelitian ini dilaksanakan secara intermitten yaitu selama satu jam mengingat adaptasi psikologi ibu post partum ibu bayi masih tergantung dengan keluarga untuk merawat bayinya. Manfaat dan keuntungan KMC antara lain dapat menstabilkan suhu tubuh, pernapasan dan denyut jantung bayi, perlindungan bayi dari infeksi, mening-katkan pertumbuhan dan perkembangan bayi, berat badan bayi cepat naik, meningkatkan keberhasilan pemberian ASI, stimulasi dini, kasih sayang/bounding (bayi merasa dicintai dan diperhatikan) menurunkan angka kematian neonatal (AKN), mengurangi biaya rumah sakit karena waktu perawatan yang pendek,tidak memerlukan inkubator dan efisiensi tenaga kesehatan (Proverawati dan Ismawati, 2010).

Hal ini sejalan dengan penelitian Almeida, dkk (2007) yang menyatakan bahwa KMC berpengaruh pada fungsi fisiologis BBLR, antara lain meningkatkan suhu tubuh, sehingga membe-rikan kontribusi terhadap perbaikan kontrol termal, peningkatan saturasi oksigen perifer, peningkatan oksigenasi jaringan dan menstabilkan pernapasan, yang membawa kenyamanan pernapasan yang lebih besar untuk BBLR.

Bayi BBLR yang mengalami hipotermi di penelitian ini mengalami peningkatan suhu setelah dilakukan KMC selama 1 jam, hal ini sejalan dengan penelitian Ibe (2004) dalam Hartini (2011) yang menyatakan bahwa terdapat perbedaan yang bermakna terhadap suhu tubuh bayi prematur sebelum dan sesudah dilakukan perawatan metode kanguru. Hasil penelitian menunjukkan semua suhu tubuh bayi yang dilakukan Perawatan metode Kanguru mengalami kenaikan yang bermakna dibanding bayi yang tidak dilakukan.

Meletakkan dan mendekapkan bayi di dada ibu merupakan salah satu cara mentransfer panas agar menjaga tubuh bayi tetap hangat, karena bayi berat badan lahir rendah mudah sekali kedinginan, dan serangan dingin dapat menyebabkan kematian pada BBLR. Kontak langsung kulit bayi dan ibu menyebabkan panas tubuh ibu menghangatkan tubuh bayi. Pada KMC, metode peningkatan suhu tubuh bayi BBLR dilakukan secara konduksi yakni perpindahan panas antara benda-benda yang berbeda suhunya berkontak lansung satu sama lain. Panas berpindah mengikuti penurunan gradient normal dari benda yang lebih panas ke yang lebih dingin. Dalam hal ini, bayi BBLR mengambil suhu tubuh ibunya secara langsung melalui kontak dari kulit ke kulit mengingat suhu tubuh ibunya lebih tinggi dari suhu tubuh bayi (Suradi, dkk, 
2008). Jadi pada tubuh bayi BBLR yang mengalami hipotermi ketika dilakukan KMC selama satu jam selain menghasilkan metabolisme panas, terjadi juga perpindahan panas tubuh ibu ke bayinya secara konduksi.

Bayi BBLR di penelitian ini yang mengalami hipertermi juga mengalami kenaikan suhu. Suhu tubuh hampir semuanya diatur oleh mekanisme persyarafan, dan hampir semua mekanisme ini terjadi melalui pusat pengaturan suhu yang terletak pada hipotalamus. Pada bayi baru lahir pusat pengaturan suhu tubuhnya belum berfungsi sempurna, sehingga mudah mengalami hipertermi oleh karena paparan suhu lingkungan yang berlebihan, infeksi, maupun dehidrasi, (Kosim, 2008). Pengaturan suhu dikendalikan oleh keseimbangan antara pembentukan panas dan kehilangan panas. Bila laju pembentukan panas di dalam tubuh lebih besar daripada laju hilangnya panas, panas akan timbul di dalam tubuh dan suhu tubuh akan meningkat, sebaliknya bila kehilangan panas lebih besar, panas tubuh dan suhu tubuh akan menurun (Silverthon, 2004).

Penelitian ini tidak sejalan dengan penelitian Hartini (2011) yang menyatakan bahwa penerapan metode kanguru dapat menurunkan suhu tubuh bayi yang mengalami demam. Perbedaan penelitian ini dengan penelitian tersebut adalah penelitian ini tidak menggunakan pemberian antipiretik sebelum melakukan $\mathrm{KMC}$, dan responden yang mengalami hipertermi di RS Pandan arang mempunyai riwayat infeksi, sepsis neonatorum dan ibu bayi juga ada sebagian yang mengalami mastitis.

Saat bayi BBLR mengalami hipertermi, hipotalamus mendeteksi suhu tubuh yang terlalu panas, tubuh akan melakukan mekanisme umpan balik. Mekanisme umpan balik ini terjadi bila suhu tubuh inti telah melewati batas toleransi tubuh untuk mempertahankan suhu, yang disebut titik tetap (set point). Titik tetap tubuh dipertahankan agar suhu tubuh inti konstan pada $37^{\circ} \mathrm{C}$, apabila suhu tubuh meningkat lebih dari titik tetap, hipotalamus akan terangsang untuk melakukan serangkaian mekanisme untuk mempertahankan suhu dengan cara menurunkan produksi panas dan meningkatkan pengeluaran panas sehingga suhu kembali pada titik tetap (Tamsuri, 2006). Hal ini dapat dilihat dari hasil suhu setelah dilakukan KMC selama satu jam meskipun mengalami kenaikan, kenaikannya haya $1^{0} \mathrm{C}-2^{0} \mathrm{C}$. Dengan penerapan KMC selama satu jam, proses kehilangan suhu tubuh dengan cara konveksi tidak terjadi. Pengeluaran panas tubuh melalui mekanisme vasodilatasi sehingga memungkinkan perpindahan panas dari tubuh ke kulit. Panas pada kulit bayi BBLR yang dilakukan KMC, tidak menghilang dikarenakan tidak terjadi perpindahan panas secara konveksi dengan udara yang lebih dingin, justru kulit bayi mengalami perpindahan panas secara konduksi yaitu kontak dengan kulit ibunya yang suhunya lebih lebih tinggi dari suhu BBLR.

\section{KESIMPULAN DAN SARAN}

Kesimpulan:

Berdasarkan penelitian ini didapatkan rata-rata suhu tubuh pada Bayi Berat Badan Lahir Rendah (BBLR) di ruang Perinatologi RSUD Pandan Arang Boyolali sebelum dan setelah pelaksanaan KMC selama satu jam hari pertama, kedua, ketiga adalah $36,66^{\circ} \mathrm{c}$ dan $37,07^{\circ} \mathrm{c}$. Terdapat pengaruh pelaksanaan 
Kangaroo Mother Care (KMC) selama satu jam terhadap suhu tubuh Bayi Berat Badan Lahir Rendah (BBLR) di ruang Perinatologi RSUD Pandan Arang Boyolali $(p<0,05)$.

Saran:

Perlunya penerapan pelaksanaan Kangaroo Mother Care (KMC) selama satu jam pada bayi berat badan lahir rendah di ruang Perinatologi khususnya RSUD Pandan Arang Boyolali untuk mengurangi ketidakstabilan suhu tubuh serta perlu adanya ruangan khusus untuk ibu bayi yang melakukan perawatan metode KMC dengan segala fasilitasnya dibeberapa rumah sakit di Indonesia.

\section{DAFTAR RUJUKAN}

Almeida, dkk. (2007). Efects of kangaroo mother care on the vital signs of low-weight preterm newborns. Brazilian journal of physical therapy Vol.11, No.1, ISSN 1413-3555

Arifah S dan Wahyuni S. (2015). Pengaruh kangaroo mother care $(\mathrm{kmc})$ dua jam dan empat jam per hari terhadap kenaikan berat badan lahir rendah bayi preterm di rs pku muhammadiyah surakarta. Jurnal Prosiding Seminar Ilmiah Nasional. ISSN: 2338-2694.

Arifah S dan Kartinah. (2008). Peran lemak coklat dalam mekanisme produksi panas pada bayi. Surakarta: Berita Ilmu Keperawatan vol.1 No.4 ISSN 1979-2697

Arikunto, S. (2002). Prosedur Penelitian Suatu Pendekatan Praktik. Jakarta: Rineka Cipta.
Bahiyatun. (2009). Buku Ajar Asuhan Kebidanan Nifas Normal. Jakarta: EGC

Dahlan, S. (2010). Metode Penelitian untuk Kesehatan. Jakarta: Arkans.

Departemen Kesehatan Republik Indonesia. (2013). Profil Kesehatan Indonesia. http://www.depkes.go.id/resource s/download/pusdatin/profilkesehatan-indonesia-2013.pdf Diunduh pada tanggal 28 Juni 2016 (17.15)

Endyarni,

Bernie. http://www.idai.or.id/artikel/klinik lasi/perawatan-metode-kangurupmk-meningkatkan-pemberianasi. Diunduh 20 Januari 2017

Hartini, Sri. (2011). Pengaruh perawatan metode kanguru terhadap suhu tubuh bayi yang mengalami demam di RS Telogorejo dan RB Mardi Rahayu Semarang. Depok: Tesis Universitas Indonesia

Jannah, AR. (2015). Pengelolaan hipertermi pada an. $F$ dengan kejang demam di ruang anggrek rsud ambarawa. Ungaran: Akademi Keperawatan Ngudi Waluyo

Karyuni, Eko dan Meilya, Eni. (2007). Buku Saku Manajemen Masalah Bayi Baru Lahir Panduan untuk Dokter, Perwat dan Bidan. Jakarta: EGC.

Kemenkes RI. (2013). Hasil Riskesdas 2013. Jakarta: Departemen Kesehatan RI.

Kosim, MS. (2008). Buku Ajar Neonatologi. Edisi pertama. Jakarta: Penerbit IDAI.

Lunze, Karsten. (2014). Prevention and management of neonatal 
hypothermia in zambia. Research article. Journals.plos.org

Notoatmodjo, S. (2010). Metode Penelitian Kesehatan. Jakarta: Rineka Cipta.

Permatasari, I.K. (2012). Perbedaan afektivitas kompres air hangat dan kompres air biasa terhadap penurunan suhu tubuh pada anak dengan demam di rsud Tugurejo Semarang. Jurnal Program Studi Ilmu Keperawatan STIKES Telogorejo Semarang.

Proverawati dan Ismawati. (2010). Berat Badan Lahir Rendah. Yogyakarta: Nuha Medika.

Rahmayanti. (2011). Pelaksanaan Perawatan Metode Kanguru pada Ibu yang Memiliki BBLR di Rumah Sakit Budi Kemuliaan Jakarta. Jakarta: Program Sarjana Kesehatan Masyarakat.

Silverthon,

D.

(2004). Human physiology: An integrated approach. 3rd ed. San Francisco: Pearson Education.

Sudarti dan Fauziah. (2013). Asuhan Neonatus Resiko Tinggi dan Kegawatan. Yogyakarta. Nuha Medika

Sugiyono. (2010). Metode Penelitian Kualitatif, Kuantitatif, $R \& D$. Bandung: Alfabeta.

Suhermi. (2009). Persalinan dan Bayi Baru Lahir. Jakarta: EGC

Suradi, R. (2008). Perawatan Bayi Berat Lahir Rendah (BBLR) Dengan Metode Kanguru. Jakarta: Departemen Kesehatan Republik Indonesia.

Surasmi A., Handayani S., Kusuma H. (2003). Perawatan Bayi Resiko Tinggi. Jakarta: EGC.
Syamsu, F A. (2013). Pengaruh Perawatan Metode Kanguru Terhadap Fungsi Fisiologis Bayi Prematur dan Kepercayaan Diri Ibu Dalam Merawat Bayi. Jurnal Keperawatan Soedirman (The Soedirman Jurnal of Nursing). Volume 8, No 3.

Tamsuri, A. (2006). Tanda Tanda Vital Suhu Tubuh. Jakarta: EGC 